\title{
Chapter 22 \\ Signaling Events in Pollen Acceptance or Rejection in the Arabidopsis Species
}

\author{
Emily Indriolo, Darya Safavian, and Daphne R. Goring
}

\begin{abstract}
The initial events of pollen-pistil interactions are fundamentally important in flowering plants because they influence successful fertilization. These early events include the recognition of pollen grains through signaling events in the pistil that will lead to the acceptance of a compatible pollen grain or the rejection of an incompatible pollen grain. There has been much research into this field in the Brassicaceae, as this family includes many agriculturally important crops such as canola, radish, turnip, and cabbage. However, this review focuses on what is known about the early pollen-pistil interactions in the experimentally tractable Arabidopsis genus, including Arabidopsis thaliana (a self-compatible species) and Arabidopsis lyrata (a self-incompatible species). Compatible pollinations are driven by the ability of the pistil to provide the resources for an acceptable pollen grain to hydrate, germinate, and fertilize the ovule. Self-incompatible species have a receptorligand signaling pathway that rejects self-pollen grains, preventing inbreeding and encouraging genetic diversity within the species. There is some overlap between these two pathways, and current research is looking for unknown elements and downstream events following the initial recognition of a pollen grain in Arabidopsis.
\end{abstract}

Keywords Compatible pollen response $\bullet$ E3 ubiquitin ligase $\bullet$ Exocyst $\bullet$ Selfincompatibility $\bullet$ Vesicle secretion

\footnotetext{
E. Indriolo • D. Safavian

Department of Cell and Systems Biology, University of Toronto,

Toronto, ON, Canada M5S 3B2

D.R. Goring $(\triangle)$

Department of Cell and Systems Biology, University of Toronto,

Toronto, ON, Canada M5S 3B2

Centre for the Analysis of Genome Evolution and Function, University of Toronto,

Toronto, ON, Canada M5S 3B2

e-mail: d.goring@utoronto.ca
} 


\subsection{Introduction}

Throughout the course of land plant evolution, various mating strategies have occurred over time, with the most recent innovation being the development of flowers. With flowers, a successful fertilization is typically determined by interactions between the male pollen and the female pistil. Therefore, a great deal of research has focused on pollenpistil interactions, and one targeted area has been uncovering the molecular and cellular mechanisms of early pollen-pistil interactions in species of the mustard family (Brassicaceae) such as the Arabidopsis and Brassica genera. In this family, selective cell-cell interaction events occur between the pollen grain and the surface of the pistil. These pollen-pistil interactions trigger an active recognition system to allow for the acceptance of compatible pollen and the subsequent successful fertilization or pollen rejection if the self-incompatibility system is activated. Much of our understanding of these early pollen-pistil interaction events has come from research on the Brassica genus (reviewed in Hiscock and Allen 2008; Chapman and Goring 2010; Iwano and Takayama 2012). This chapter largely focuses on reviewing the early stages following compatible and self-incompatible pollinations for the closely related Arabidopsis genus.

\subsection{Early Compatible Pollen-Pistil Interactions in Arabidopsis thaliana}

Pollen first comes in contact with the stigma at the top of the pistil, and the ability of the stigma to discriminate between compatible and other foreign pollen depends on whether the plant possesses wet- or dry-type stigmas. Wet stigmas have abundant surface secretions that indiscriminately capture pollen and allow germination to occur. In contrast, surface secretions are absent in dry stigmas, and as a result there is a much tighter regulation of these early pollen-stigma interaction stages (Dickinson 1995). Arabidopsis species possesses a dry stigma that is covered with papillae on the stigmatic surface. Once a compatible pollen grain comes in contact with a stigmatic papilla, the early stages of pollen capture and adhesion, pollen hydration, and germination are closely regulated (Elleman et al. 1992; Preuss et al. 1993; Kandasamy et al. 1994; Zinkl et al. 1999). The ability to conduct genetic screens with relative ease in A. thaliana has aided in identifying a number of factors that regulate pollen-stigma interactions (Preuss et al. 1993; Hulskamp et al. 1995; Nishikawa et al. 2005).

\subsubsection{Pollen-Stigma Components for Compatible Pollen Acceptance}

Following pollination, two components of the pollen grain come in contact with the stigmatic papilla: the exine, which is the sculptured outermost layer of the pollen grain, and the lipid- and protein-rich pollen coat that is present in the pockets of the 
exine (Elleman et al. 1992; Kandasamy et al. 1994). The initial binding of compatible A. thaliana pollen to the stigmatic papilla was determined to be mediated by the pollen exine, while the pollen coat was not required (Zinkl et al. 1999). Consistent with this, a genetic screen for mutants disrupted in this initial adhesion stage resulted in a number of mutants with exine defects (Nishikawa et al. 2005; Dobritsa et al. 2011). The pollen coat is then involved in further adhesion of the pollen grain to the stigmatic papilla. At this stage, the pollen coat flows out from the pollen grain toward the stigmatic papilla to mix with the lipidic and proteinaceous surface of the stigmatic papilla, creating a more robust connection at the pollen-stigma interface (Elleman et al. 1992; Preuss et al. 1993; Kandasamy et al. 1994; Zinkl et al. 1999). The result is an interface between the pollen grain and the papilla where signaling is hypothesized to occur, and water is transferred from the papilla to the pollen grain for hydration (Elleman and Dickinson 1990; Preuss et al. 1993).

Pollen hydration is necessary for the desiccated pollen grain to become metabolically active and proceed to the next stage of pollen germination and formation of a pollen tube, and components of the pollen-stigma interface are important to this process (Preuss et al. 1993). On the female side, the specific lipid content in the stigmatic cuticle was indirectly implicated in the control of pollen hydration through the study of the A. thaliana fiddlehead (fdh) mutant. Normally, pollen hydration and pollen tube growth are restricted to mature stigmas and cannot be supported on other tissues (Kandasamy et al. 1994; Ma et al. 2012). However, the $f d h$ mutant allowed pollen hydration and pollen tube growth to occur on nonstigmatic surfaces such as the entire shoot epidermis (Lolle and Cheung 1993). Interestingly, $f d h$ mutant leaves were found to have increased levels of long-chain lipids, and the FDH gene is predicted to encode an enzyme involved in lipid biosynthesis (Lolle et al. 1997; Yephremov et al. 1999; Pruitt et al. 2000).

The importance of pollen coat lipids in the hydration process was determined by the study of impaired pollen hydration in A. thaliana eceriferum (cer) mutants (Preuss et al. 1993; Hulskamp et al. 1995). The cer mutants have defects in the long-chain lipid synthesis, and there was a reduction or loss of pollen coat on the surface of the cer mutant pollen grains. As a result, these pollen grains failed to hydrate on the stigma, but this defect could be rescued by high environmental humidity where normal pollen hydration, pollen tube growth, and successful seed set were observed (Preuss et al. 1993; Hulskamp et al. 1995). Thus, work on the $c e r$ and $f d h$ mutants suggests that long-chain lipids are required on both surfaces (i.e., the pollen and the stigma) to support pollen hydration.

Although the molecular mechanism of water transfer from the stigmatic papilla to the pollen grain has yet to be determined, changes to the impermeable pollen coat with the formation of the pollen-stigma interface are proposed to create a passageway for water to flow from the stigma to the pollen grain (Elleman and Dickinson 1986; Elleman et al. 1992; Murphy 2006). This may involve changes in the lipid properties of the pollen-stigma interface through the actions of lipid-binding oleosin-like proteins or lipases that have been identified in the A. thaliana pollen coat (Mayfield et al. 2001). For example, the pollen glycine-rich protein 17 (GRP17) contains an oleosin domain that has been implicated in this role (Mayfield and 
Preuss 2000). The A. thaliana grp17 mutant produced pollen grains that were slower in initiation of pollen hydration, although the rate of hydration, once initiated, was similar to the wild type. Compared to wild-type pollen, the grp17 mutant pollen had a visibly similar pollen coat with a similar lipid composition but was lacking the GRP17 protein (Mayfield and Preuss 2000). Lipids in the pollenstigma interface may also be enzymatically modified by lipases such as extracellular lipase 4 (EXL4) (Updegraff et al. 2009). A mutation in the EXL4 gene also resulted in changes to pollen hydration. The exl4 mutant pollen had a pollen coat that was normal in appearance and had a similar lipid profile to wild-type pollen but had reduced esterase activity. Interestingly, the exl4 mutant pollen initiated hydration at a similar time to wild-type pollen but then displayed a slower rate of hydration (Updegraff et al. 2009). Both the grp17 and exl4 mutants displayed mild hydration phenotypes, and it may be that multiple members of the corresponding gene families (Mayfield et al. 2001) need to be knocked out to see a more pronounced hydration defect. Other unknown factors may are also involved in controlling pollen hydration.

Following pollen hydration and germination, the emerging pollen tube penetrates the cell wall of the stigmatic papilla. Changes at the A. thaliana stigmatic surface were observed after compatible pollen attachment, including the expansion of the outer layer of the cell wall beneath the grain (Elleman et al. 1992; Kandasamy et al. 1994). In B. oleracea, the expansion of the outer layer of the stigmatic cell wall appears to be initiated by factors in the pollen coating as application of isolated pollen coat extracts to the stigma was found to cause cell wall expansion (Elleman and Dickinson 1996). To facilitate the penetration of the developing pollen tube into the stigmatic papillar surface, hydrolytic enzymes from both the pollen and the stigma are thought to cause the breakdown of the waxy cuticle and the underlying cell wall of the stigmatic papilla (Dickinson 1995); these may include enzymes such as serine esterases, cutinases, polygalacturonases, pectin esterases, and expansins (Hiscock and Allen 2008). A. thaliana microarray experiments have identified predicted genes for these various enzymes to be enriched in their expression in the pollen (Honys and Twell 2003) or the stigma (Swanson et al. 2005; Tung et al. 2005). A specific example is the A. thaliana VANGUARD1 (VGD1) gene, which encodes a pectin methylesterase and is expressed in the pollen grain and pollen tube. VGD1 is required for pollen tube growth through the pistil as the $v g d l$ mutant displayed reduced levels of pectin methylesterase activity in the pollen grain and the pollen tube growth proceeded at a much slower rate compared to wild-type pollen (Jiang et al. 2005). After a pollen tube grows through the stigmatic papillar cell wall to the base of the stigma, it enters into the transmitting tract, growing down to an ovule, where fertilization takes place (Lennon et al. 1998; Cheung et al. 2010). A number of factors have also been identified for these later stages (Kessler and Grossniklaus 2011; Takeuchi and Higashiyama 2011). 


\subsubsection{Signaling Events in the Stigmatic Papilla Regulating Pollen Hydration and Germination}

With the stigmatic papilla controlling the very early postpollination stages, starting with pollen adhesion, a specific signaling event is proposed to occur upon contact with compatible pollen. A number of small pollen coat proteins could potentially act as signaling molecules for putative receptors in the stigma papilla (Mayfield et al. 2001; Vanoosthuyse et al. 2001), and several Brassica candidates for promoting pollen adhesion have been proposed (Doughty et al. 1998; Luu et al. 1997, 1999; Takayama et al. 2000a). However, there are likely other unknown signaling proteins responsible for activating a cellular response in the stigmatic papilla to promote acceptance of the compatible pollen grain. These secretory vesicles to the specified sites responses include $\mathrm{Ca}^{2+}$ spikes, actin polymerization, and microtubule depolymerization, and these events may be linked to polarized exocytosis toward the pollen attachment site, as described next. In Brassica rapa, both an actin network and vacuolar network were observed to be established in a direction toward the compatible pollen grain during pollen hydration (Iwano et al. 2007). In B. napus and $A$. thaliana, disruption of the microtubule network resulted in increased acceptance of compatible pollen, indicating that microtubule depolymerization is important to this process (Samuel et al. 2011). $\mathrm{Ca}^{2+}$ dynamics in the stigmatic papillae were monitored in vivo using transgenic $A$. thaliana plants expressing the yellow cameleon 3.1, a $\mathrm{Ca}^{2+}$ indicator that can be used to monitor rapid changes in $\mathrm{Ca}^{2+}$ cytoplasmic concentrations (Iwano et al. 2004). Although no increase of $\left[\mathrm{Ca}^{2+}\right]$ was observed in unpollinated stigmatic papillae, several increases were observed in the stigmatic papillae following pollination. The first increase in $\left[\mathrm{Ca}^{2+}\right]$ took place in the stigmatic papilla underneath the pollen contact site during the pollen hydration period. A second local increase in $\left[\mathrm{Ca}^{2+}\right]$ occurred in the stigmatic papilla, again under the pollen attachment site, with pollen germination. Finally, the third and strongest increase in local $\left[\mathrm{Ca}^{2+}\right]$ occurred with pollen tube penetration of the stigmatic papilla (Iwano et al. 2004). Thus, these $\mathrm{Ca}^{2+}$ spikes in the stigmatic papilla underneath the pollen-pistil interface support the premise that the stigmatic papilla responds to the compatible pollen and controls these early postpollination stages.

More recently, Exo70A1 has been identified as a factor required in the stigma for the early responses of the stigmatic papilla to the compatible pollen (Samuel et al. 2009). Exo70A1 is a subunit of the exocyst, an evolutionary conserved protein complex in eukaryotes consisting of eight subunits: Sec3, Sec5, Sec6, Sec8, Sec10, Sec15, Exo70, and Exo84 (Hsu et al. 1996; TerBush et al. 1996; Hala et al. 2008). Some of the exocyst subunit genes are present in multiple copies in plant genomes, and Exo70A1 is one member of the Exo70 gene family in A. thaliana (Synek et al. 2006; Chong et al. 2010). In yeast and animal systems, the exocyst was determined to act as a tethering complex to dock secretory vesicles to the plasma membrane for polar secretion, and various small GTPases have been found to interact with exocyst 
subunits to regulate the assembly, localization, and function of this complex (reviewed in He and Guo 2009; Heider and Munson 2012). Once the vesicles have been tethered at the plasma membrane by the exocyst complex, the SNARE complex catalyzes the fusion of the secretory vesicle to the plasma membrane (Whyte and Munro 2002).

Exo70A1 was identified through work on the self-incompatibility pathway (described in the next section), and this led to the establishment of its role in compatible pollen response in both B. napus and A. thaliana (Samuel et al. 2009). The A. thaliana exo70A1 mutant displayed a loss of pollen hydration and pollen tube growth when wild-type pollen was placed on the exo70Al mutant stigma (Samuel et al. 2009). Furthermore, this stigmatic defect was rescued by the stigma-specific expression of an RFP:Exo70A1 fusion protein in the A. thaliana exo70A1 mutant. Confocal microscopy revealed that RFP:Exo70A1 protein was localized to the apical plasma membrane of mature stigmatic papillae (Samuel et al. 2009).

In yeast, Sec3 and Exo70 were found to be located at the plasma membrane before exocyst assembly (Finger et al. 1998; Boyd et al. 2004). Thus, Exo70A1 may play a similar role of being present at the stigmatic papillar plasma membrane before pollination and exocyst assembly. In yeast and mammalian cells, Sec3 and Exo70 were also found to be recruited to the plasma membrane via binding to phosphatidylinositol-4,5-bisphosphate, located at the inner leaflet of the plasma membrane (He et al. 2007; Liu et al. 2007; Zhang et al. 2008). Interestingly, when A. thaliana mutants with altered phosphoinositide pools were tested in pollen hydrations assays, wild-type pollen grains were found to have reduced hydration rates on the mutant stigmas, suggesting that specific membrane lipids are also important for these pollen-stigma interactions (Chapman and Goring 2011). Finally, in yeast, the polarized localization of the exocyst has been found to be controlled by the Rho GTPases, Cdc42, Rho1, and Rho3, through interactions with the Sec3 and Exo70 subunits (Robinson et al. 1999; Guo et al. 2001; Zhang et al. 2001; Wu et al. 2010). Exocyst assembly then occurs through an actin-dependent recruitment of the remaining exocyst subunits with the secretory vesicles to the specified sites on the plasma membrane for exocytosis (Boyd et al. 2004; Zhang et al. 2005).

Although RFP:Exo70A1 was localized to the entire stigmatic papillar apical plasma membrane, one would predict that exocyst assembly and vesicle docking would occur in a more localized area, just under the pollen contact site (Samuel et al. 2009). Consistent with this, we have observed, with compatible pollinations in A. thaliana and A. lyrata, that vesicle-like structures were observed fusing to the papillar plasma membrane under the pollen contact site (Safavian and Goring 2013). This step would require some type of unknown signal, possibly through Exo70A1, to regulate exocyst assembly and secretory vesicle docking under the pollen contact site (Fig. 22.1). The cargo of these secretory vesicles is also unknown, but they presumably contain stigmatic resources for pollen hydration and pollen tube penetration that are released upon fusion with the papillar plasma membrane and with the subsequent discharge of the contents into the apoplastic space. One such candidate cargo could be plasma membrane aquaporins, which could facilitate water transfer (Verdoucq et al. 2008; Postaire et al. 2010) from the stigmatic papilla to the 


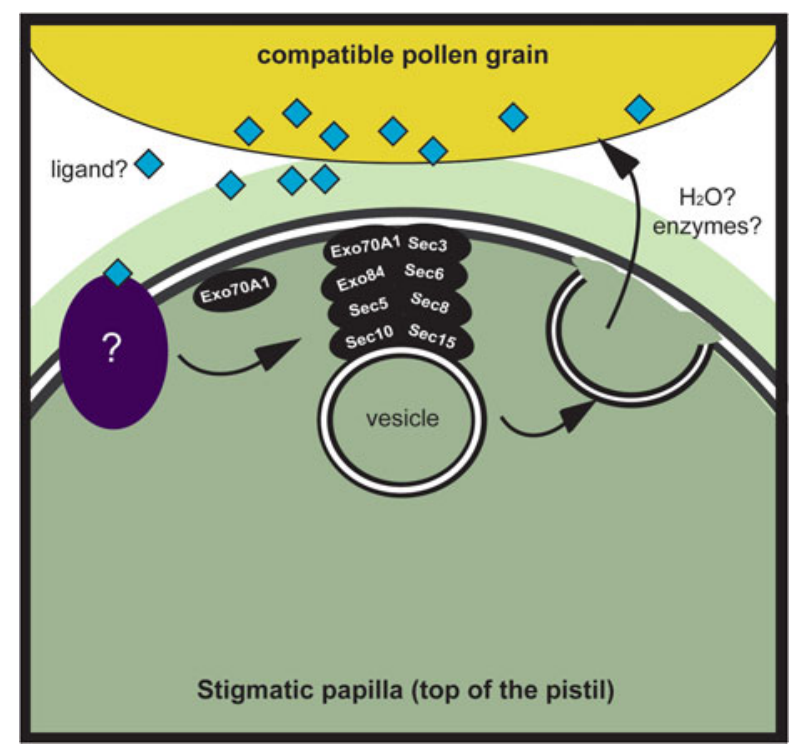

Fig. 22.1 Model of compatible pollen-pistil interactions in Arabidopsis. When a compatible pollen grain lands on the stigmatic papilla, an unknown factor or ligand is proposed to be detected by an unknown receptor in the papilla. Polarized vesicle secretion is then targeted to the pollen contact site by the exocyst complex. These vesicles are hypothesized to deliver factors to allow for the transfer of water from the papilla to the pollen grain and to deliver cell wall modification enzymes. The compatible pollen grain is then able to hydrate, and the pollen tube penetrates the stigma to continue onto an ovule or fertilization

pollen grain for hydration. As well, the vesicles may deliver cell wall-modifying enzymes for stigmatic papillar cell wall loosening and pollen tube penetration (Elleman and Dickinson 1996; Samuel et al. 2009).

\subsection{Self-Incompatibility in the Genus Arabidopsis}

Because plants are sessile in nature, flowering plants have evolved various mechanisms to aid in mate selection, and one of those methods is through the development of a self-incompatibility system. In the Brassicaceae, the self-incompatibility system allows the stigma to reject self-pollen and allows for the acceptance of genetically diverse non-self pollen (reviewed in Charlesworth and Vekemans 2005; Iwano and Takayama 2012). Two components control this system: the female pistil determinant, $S$ receptor kinase (SRK; Takasaki et al. 2000; Silva et al. 2001), and the male pollen ligand, $S$-locus cysteine-rich/S-locus protein 11 (SCR/SP11; Schopfer et al. 1999; Takayama et al. 2000b). The two genes encoding these proteins are highly polymorphic (referred to as $S$-haplotypes), first identified in 
Brassica species (Haasen and Goring 2010), and have been characterized in other Brassicaceae species, including A. lyrata (Kusaba et al. 2001; Schierup et al. 2001; Mable et al. 2005) and Capsella grandiflora (Paetsch et al. 2006; Boggs et al. 2009; Guo et al. 2009). Although much of the research into the self-incompatibility pathway has been performed in the Brassica genus, recent discoveries in the Arabidopsis genus are described here.

A. thaliana is a self-compatible species that has lost its self-incompatibility system by the pseudogenization of the SCR/SPI1 and SRK genes (Kusaba et al. 2001; Bechsgaard et al. 2006; Tang et al. 2007; Shimizu et al. 2008; Guo et al. 2011). As A. thaliana is easily transformed, a number of studies have reintroduced the $S C R /$ $S P 11$ or $S R K$ genes from other Brassicaceae species in an attempt to reintroduce the self-incompatibility trait (Bi et al. 2000; Nasrallah et al. 2002). One approach was to transform SCR/SP11-SRK S-haplotypes from A. lyrata and C. grandiflora into different $A$. thaliana ecotypes. In some ecotypes such as C24, Cvi-0, Hodja, Kas-2, and Shadara, the expression of these $S C R / S P 11$ and $S R K$ genes was able to cause self-pollen rejection while other ecotypes such as Col-0, Mt-0, Nd-0, No, RLD, and Ws-0 remained self-compatible (Nasrallah et al. 2004; Boggs et al. 2009). Although both the $S C R / S P I 1$ and $S R K$ genes are disrupted in many of the A. thaliana ecotypes, Tsuchimatsu et al. (2010) identified some $A$. thaliana ecotypes carrying an intact $S R K$ gene. Wei-1 was one of these ecotypes with a functional copy of $S R K a$, but $S C R a$ was nonfunctional because of an inversion in the gene coding region (Tsuchimatsu et al. 2010). Transformation of a restored SCRa gene into Wei-1 plants resulted in these plants displaying a self-incompatibility phenotype. Interestingly, these plants displayed a change over the course of development, going from being self-incompatible to becoming pseudo-self-compatible; that is, as the flowers became older they were able to accept self-pollen grains that were previously rejected (Tsuchimatsu et al. 2010). As a result of these studies, it was concluded that $S C R / S P 11$ and $S R K$ were the only components required to restore the self-incompatibility trait in A. thaliana ecotypes. However, the stability of the selfincompatibility trait was variable, depending on the ecotype being used for the transformation studies. This lack of a completely stable self-incompatibility phenotype in A. thaliana may be the result of variation in the A. thaliana ecotypes studied, or additional factors such as the $A R C l$ gene may be required, as discussed in more detail next.

In Brassica, the pollen SCR/SP11 ligand, present in the pollen coat, crosses the pollen-papillar interface to bind to the papillar membrane-localized SRK, and SRK becomes phosphorylated (Kachroo et al. 2001; Takayama et al. 2001; Shimosato et al. 2007). SRK exists as a homodimer and is proposed to interact as a transient complex with the $M$ locus protein kinase (MLPK) (Murase et al. 2004; Kakita et al. 2007a, b). B. rapa MLPK is a receptor-like cytoplasmic kinase that is also localized to the plasma membrane in the stigma (Murase et al. 2004). MLPK exists as two splice variants with different $\mathrm{N}$-terminal ends. MLPKf1 is generally expressed in a broad range of tissues and encodes a protein with an $\mathrm{N}$-terminal myristoylation site, whereas MLPKf2 was found to be stigma specific in expression and has an 
N-terminal hydrophobic domain (Kakita et al. 2007a). A. thaliana APKlb is the orthologue to B. rapa MLPK, and it has a similar pattern of expression with the two different isoforms that encode the same protein variants, one with an $\mathrm{N}$-terminal myristoylation site (APKIbfl) and the other with the $\mathrm{N}$-terminal hydrophobic region (APK1bf2). Despite the different N-terminal motifs between MLPKf1 and MLPKf2, both the MLPK variants localized to the plasma membrane through their respective $\mathrm{N}$-terminal domains. Both isoforms also interacted with SRK at the plasma membrane, but the interaction was lost if the $\mathrm{N}$-terminal domain was removed (Kakita et al. 2007a, b). Finally, both isoforms could rescue the mlpk mutation in B. rapa, restoring the self-incompatibility response (Kakita et al. 2007a). A similar role for A. thaliana APK1b in the self-incompatibility response has yet to be established. An apklb knockout mutant in the A. thaliana Col-0 ecotype did not show any differences from the wild type when the $S C R / S P 11$ and $S R K$ transgenes were expressed (Rea et al. 2010; Kitashiba et al. 2011). However, because the transgenic SCR/ SP11-SRK A. thaliana Col-0 plants only display a very weak self-incompatibility response and remain self-compatible (Nasrallah et al. 2002, 2004), it would be difficult to make a definitive conclusion on the role of $A P K 1 b$ in A. thaliana self-incompatibility.

In the Brassicaceae, the self-incompatibility signaling pathway is rapidly activated in the stigmatic papilla following contact with a self-pollen grain. The end result of this pathway is pollen rejection by preventing compatible pollen responses such as pollen grain hydration and pollen tube penetration into the stigma (described under compatible pollinations; Dickinson 1995). Following SCR/SP11 binding to SRK, the SRK-MLPK complex is proposed to recruit the ARM repeat-containing 1 (ARC1) E3-ubiquitin ligase (Stone et al. 2003; Samuel et al. 2008). B. napus ARC1 was the first downstream signaling component identified for SRK and was shown to be required for the rejection of self-pollen (Gu et al. 1998; Stone et al. 1999). Our most recent research into the $A R C l$ orthologue in A. lyrata has revealed that it is necessary for the self-incompatibility response in A. lyrata, similar to B. napus (Indriolo et al. 2012). Previously, ARC1 was proposed to be not required in transgenic SCR/SRK A. thaliana plants for restoring the self-incompatibility trait because the ARC1 gene was deleted from the A. thaliana genome (Kitashiba et al. 2011). Given that the strength of the self-incompatibility trait varied depending which A. thaliana ecotype was used to transform with the SCR and SRK genes, we further explored the extent of the ARCl gene deletion. An additional 355 ecotypes were surveyed by polymerase chain reaction (PCR), and in all cases, $A R C l$ was determined to be deleted (Indriolo et al. 2012), including ecotypes such as Wei-1 that contained a functional SRK gene (Tsuchimatsu et al. 2010). These data demonstrated that the functional $A R C 1$ gene was likely lost in A. thaliana before the loss of a functional $S R K$ and $S C R / S P 11$ and perhaps aided in the breakdown of selfincompatibility to self-compatibility in A. thaliana. A broader bioinformatics survey of the presence or absence of $A R C 1$ in several Brassicaceae sequenced genomes gave further support to this idea. This survey included the self-incompatible species of B. rapa, A. lyrata, and Capsella grandiflora and the self-compatible species of 
A. thaliana, Aethionema arabicum, Capsella rubella, Leavenworthia alabamica, Thellungiella halophila, Thellungiella parvula, and Sysimbrium irio. It was determined that the $A R C l$ gene was frequently deleted in self-compatible species including A. thaliana, A. arabicum, L. alabamica, T. halophila, and T. parvula whereas it was always found in the genomes of self-incompatible species (Indriolo et al. 2012). This observation was specific to the $A R C 1$ gene as the most closely related $A R C 1$ paralogue, $P U B 17$, was completely conserved in all the genomes surveyed (Indriolo et al. 2012). Therefore, the presence or absence of $A R C l$ appeared to correlate with a switch from self-incompatibility to self-compatibility in the Brassicaceae.

To directly address the requirement of ARC1 for the self-incompatibility trait in Arabidopsis, ARC1 was characterized in a natural self-incompatible species, A. lyrata. Basic characterization determined that $A R C l$ was found to be more highly expressed in the pistil, similar to B. napus $A R C 1$, which was shown to be most highly expressed in the stigma (Gu et al. 1998; Indriolo et al. 2012). The expression of $A R C l$ was then knocked down in A. lyrata by the use of $A R C l$ RNAi construct. Similar to previous observations in B. napus, transgenic ARC1 RNAi A. lyrata plants exhibited a partial breakdown in the self-incompatibility response, leading to the acceptance of self-pollen and partial seed set (Indriolo et al. 2012). As a result of the aforementioned data regarding self-incompatibility in Brassica spp. and A. lyrata, one can conclude that the role of ARC1 is conserved in the selfincompatibility signaling pathway in the core Brassicaceae (Indriolo et al. 2012).

Because the self-incompatibility pathway caused pollen rejection by inhibiting the early postpollination stages (pollen hydration, pollen tube penetration), compatibility factors in the stigmatic papilla would be predicted to be inhibited as part of this response. Following from this, the role of ARC1 in the self-incompatibility pathway was proposed to promote the ubiquitination and degradation of the proposed compatibility factors by the $26 \mathrm{~S}$ proteasome (Stone et al. 2003). Through an ARC1-interaction screen, Exo70A1 was identified as a candidate compatibility factor targeted by ARC1 (Samuel et al. 2009). As described earlier in the compatible pollen-stigma interactions section, Exo70A1 is a component of the exocyst complex for tethering secretory vesicles at the plasma membrane and is required in the stigmatic papilla for accepting compatible pollen (Samuel et al. 2009). Therefore, the inhibition or removal of Exo70A1 through ubiquitination via ARC1 would block secretory vesicles from fusing to the papillar plasma membrane underneath the pollen contact site, resulting in pollen rejection (Fig. 22.2). This model was tested in A. lyrata where both self-incompatible and cross-compatible pollinations can be followed. At 10 min after a cross-compatible pollination, vesicle-like structures were observed fusing to the papillar plasma membrane under the pollen contact site (Safavian and Goring 2013). However, at $10 \mathrm{~min}$ after a self-incompatible pollination, there was a complete absence of these vesicle-like structures at the papillar plasma membrane, and autophagic bodies were detected in the vacuole; thus supporting the inhibition of vesicle secretion as part of the self-incompatibility response (Safavian and Goring 2013). 


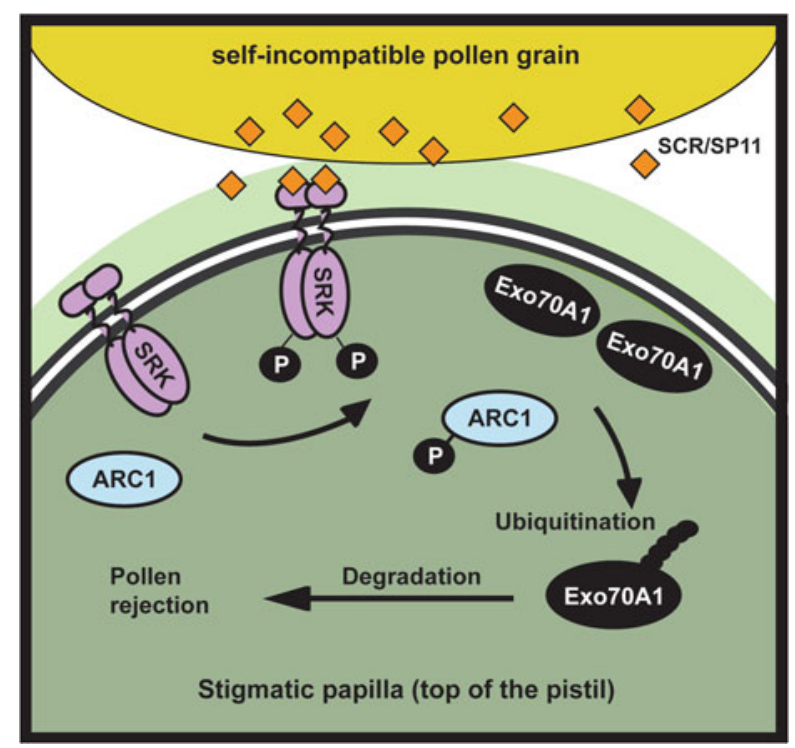

Fig. 22.2 Model of self-incompatible pollen-pistil interactions in Arabidopsis. When a self-incompatible pollen grain lands on the stigmatic papilla, the SCR/SP11 pollen ligand binds to the homodimeric receptor, $S R K$, in the stigmatic papilla. SRK then becomes phosphorylated and activated, and is proposed to phosphorylate ARC1. Phosphorylated ARC1 is then proposed to find its target, Exo70A1, at the plasma membrane. ARC1 ubiquinates Exo70A1, and Exo70A1 is targeted to the $26 \mathrm{~S}$ proteosome where it is then degraded. The removal of Exo70A1 prevents exocyst assembly and the delivery of vesicles to the pollen contact site. As a result, the self-pollen grain is rejected as it is unable to hydrate and the pollen tube cannot penetrate the stigmatic surface

\subsection{Conclusions and Future Directions}

Much progress has been made recently into the mechanisms underlying pollenpistil interactions in the Arabidopsis genus, but it is quite clear that much still remains unknown. For example, it is surprising that so little is known about what underlies a compatible interaction, such as a putative ligand and receptor to signal a compatible pollen recognition pathway in the stigma. What is clear is that downstream of this pathway, the exocyst complex is required for hydration and pollen tube penetration of compatible pollen in A. thaliana and B. napus (Samuel et al. 2009). Interestingly, following self-incompatible pollination in B. napus, moderate changes in the microtubule network were seen at the apical region of stigmatic papillae where longer microtubule bundles were observed instead of the dense network in unpollinated papillae, although no microtubule shortening or depolymerization was documented. However, a more dramatic localized depolymerization of the microtubule network was observed during compatible pollinations (Samuel et al. 2011). This distinct localized breakdown of the microtubule network was 
proposed to be regulated by Exo70A1, triggering successful pollination. Thus, the relationships between the exocyst complex, vesicle secretion, actin polymerization, and microtubule depolymerization is an area for further investigation.

The role of Exo70A1 in compatible pollinations came from its identification in the self-incompatibility signaling pathway in B. napus as a target for degradation by ARC1, downstream of the SRK-MLPK complex. Interestingly, the SRK-MLPKARC1 module appears to be used in other members in these gene families. For example, in plant innate immunity, the BIK1 receptor-like cytoplasmic kinase is part of a complex that includes the FLS2 receptor kinase, the BAK1 receptor-like kinase, and two ARC1-related proteins, PUB12 and PUB13 (Lu et al. 2011). Following bacterial flagellin recognition by FLS2, BIK1 was shown to enhance the ability of BAK1 to phosphorylate PUB13 (Lu et al. 2011). Similarly, using an in vitro assay, MPLK was found to be much more efficient at phosphorylating B. napus ARC1 compared to SRK (Samuel et al. 2008).

Other future research directions that may follow from recent discoveries include further investigating the role of ARC1, the MLPK orthologue, APK1b, and Exo70A1 in Arabidopsis species. For example, A. lyrata ARC1 could be transformed into A. thaliana expressing the A. lyrata SRK and SCR/SP11 genes to determine if a more robust self-incompatibility phenotype is generated. A. thaliana Col-0 was previously found to lack a strong self-incompatibility response with only A. lyrata SRK and SCR/SP11 being expressed (Nasrallah et al. 2002, 2004), and we have some preliminary data that show a much stronger self-incompatibility response when all three A. lyrata genes are expressed in the A. thaliana Col-0 ecotype. Another direction is to further examine the role of the Exo70A1 orthologue in A. lyrata to investigate if Exo70A1 is targeted for degradation by ARC1 following a self-incompatible pollination. Finally, the ability of some A. thaliana ecotypes to mount varying degrees of self-incompatibility responses in the absence of ARC1 support that there are still other signaling components to be discovered in this pathway. With the greater access to bioinformatics and genomics tools in the Brassicaceae, it will be much easier to find candidate genes and perform research in a similar fashion to the Arabidopsis species in regard to both compatible and self-incompatible pollinations.

Open Access: This article is distributed under the terms of the Creative Commons Attribution Noncommercial License which permits any noncommercial use, distribution, and reproduction in any medium, provided the original author(s) and source are credited.

\section{References}

Bechsgaard JS, Castric V, Charlesworth D, Vekemans X, Schierup MH (2006) The transition to self-compatibility in Arabidopsis thaliana and evolution within S-haplotypes over $10 \mathrm{Myr}$. Mol Biol Evol 23(9):1741-1750

Bi YM, Brugiere N, Cui Y, Goring DR, Rothstein SJ (2000) Transformation of Arabidopsis with a Brassica SLG/SRK region and ARC1 gene is not sufficient to transfer the self-incompatibility phenotype. Mol Gen Genet 263(4):648-654 
Boggs NA, Dwyer KG, Shah P, McCulloch AA, Bechsgaard J, Schierup MH, Nasrallah ME, Nasrallah JB (2009) Expression of distinct self-incompatibility specificities in Arabidopsis thaliana. Genetics 182(4):1313-1321

Boyd C, Hughes T, Pypaert M, Novick P (2004) Vesicles carry most exocyst subunits to exocytic sites marked by the remaining two subunits, Sec3p and Exo70p. J Cell Biol 167(5):889-901

Chapman LA, Goring DR (2010) Pollen-pistil interactions regulating successful fertilization in the Brassicaceae. J Exp Bot 61(7):1987-1999

Chapman LA, Goring DR (2011) Misregulation of phosphoinositides in Arabidopsis thaliana decreases pollen hydration and maternal fertility. Sex Plant Reprod 24(4):319-326

Charlesworth D, Vekemans X (2005) How and when did Arabidopsis thaliana become highly selffertilising. Bioessays 27(5):472-476

Cheung AY, Boavida LC, Aggarwal M, Wu HM, Feijo JA (2010) The pollen tube journey in the pistil and imaging the in vivo process by two-photon microscopy. J Exp Bot 61(7):1907-1915

Chong YT, Gidda SK, Sanford C, Parkinson J, Mullen RT, Goring DR (2010) Characterization of the Arabidopsis thaliana exocyst complex gene families by phylogenetic, expression profiling, and subcellular localization studies. New Phytol 185(2):401-419

Dickinson HG (1995) Dry stigmas, water and self-incompatibility in Brassica. Sex Plant Reprod 8:1-10

Dobritsa AA, Geanconteri A, Shrestha J, Carlson A, Kooyers N, Coerper D, Urbanczyk-Wochniak E, Bench BJ, Sumner LW, Swanson R, Preuss D (2011) A large-scale genetic screen in Arabidopsis to identify genes involved in pollen exine production. Plant Physiol 157(2): 947-970

Doughty J, Dixon S, Hiscock SJ, Willis AC, Parkin IA, Dickinson HG (1998) PCP-A1, a defensinlike Brassica pollen coat protein that binds the S locus glycoprotein, is the product of gametophytic gene expression. Plant Cell 10(8):1333-1347

Elleman CJ, Dickinson HG (1986) Pollen-stigma interactions in Brassica. IV. Structural reorganization in the pollen grains during hydration. J Cell Sci 80:141-157

Elleman CJ, Dickinson HG (1990) The role of the exine coating in pollen-stigma interactions in Brassica oleracea. New Phytol 114:511-518

Elleman CJ, Dickinson HG (1996) Identification of pollen components regulating pollinationspecific responses in the stigmatic papillae of Brassica oleracea. New Phytol 133(2):197-205

Elleman CJ, Franklin-Tong V, Dickinson HG (1992) Pollination in species with dry stigmas: the nature of the early stigmatic response and the pathway taken by pollen tubes. New Phytol 121:413-424

Finger FP, Hughes TE, Novick P (1998) Sec3p is a spatial landmark for polarized secretion in budding yeast. Cell 92(4):559-571

Gu T, Mazzurco M, Sulaman W, Matias DD, Goring DR (1998) Binding of an arm repeat protein to the kinase domain of the S-locus receptor kinase. Proc Natl Acad Sci USA 95(1):382-387

Guo W, Tamanoi F, Novick P (2001) Spatial regulation of the exocyst complex by Rho1 GTPase. Nat Cell Biol 3(4):353-360

Guo YL, Bechsgaard JS, Slotte T, Neuffer B, Lascoux M, Weigel D, Schierup MH (2009) Recent speciation of Capsella rubella from Capsella grandiflora, associated with loss of selfincompatibility and an extreme bottleneck. Proc Natl Acad Sci USA 106(13):5246-5251

Guo YL, Zhao X, Lanz C, Weigel D (2011) Evolution of the S-locus region in Arabidopsis relatives. Plant Physiol 157(2):937-946

Haasen KE, Goring DR (2010) The recognition and rejection of self-incompatible pollen in the Brassicaceae. Bot Stud 51(1):1-6

Hala M, Cole R, Synek L, Drdova E, Pecenkova T, Nordheim A, Lamkemeyer T, Madlung J, Hochholdinger F, Fowler JE, Zarsky V (2008) An exocyst complex functions in plant cell growth in Arabidopsis and tobacco. Plant Cell 20(5):1330-1345

He B, Guo W (2009) The exocyst complex in polarized exocytosis. Curr Opin Cell Biol 21(4):537-542

He B, Xi F, Zhang X, Zhang J, Guo W (2007) Exo70 interacts with phospholipids and mediates the targeting of the exocyst to the plasma membrane. EMBO J 26(18):4053-4065 
Heider MR, Munson M (2012) Exorcising the exocyst complex. Traffic 13(7):898-907

Hiscock SJ, Allen AM (2008) Diverse cell signalling pathways regulate pollen-stigma interactions: the search for consensus. New Phytol 179(2):286-317

Honys D, Twell D (2003) Comparative analysis of the Arabidopsis pollen transcriptome. Plant Physiol 132(2):640-652

Hsu SC, Ting AE, Hazuka CD, Davanger S, Kenny JW, Kee Y, Scheller RH (1996) The mammalian brain rsec6/8 complex. Neuron 17(6):1209-1219

Hulskamp M, Kopczak SD, Horejsi TF, Kihl BK, Pruitt RE (1995) Identification of genes required for pollen-stigma recognition in Arabidopsis thaliana. Plant J 8(5):703-714

Indriolo E, Tharmapalan P, Wright SI, Goring DR (2012) The ARC1 E3 ligase gene is frequently deleted in self-compatible Brassicaceae species and has a conserved role in Arabidopsis lyrata self-pollen rejection. Plant Cell 24(11):4607-4620

Iwano M, Takayama S (2012) Self/non-self discrimination in angiosperm self-incompatibility. Curr Opin Plant Biol 15(1):78-83

Iwano M, Shiba H, Miwa T, Che FS, Takayama S, Nagai T, Miyawaki A, Isogai A (2004) $\mathrm{Ca}^{2+}$ dynamics in a pollen grain and papilla cell during pollination of Arabidopsis. Plant Physiol 136(3):3562-3571

Iwano M, Shiba H, Matoba K, Miwa T, Funato M, Entani T, Nakayama P, Shimosato H, Takaoka A, Isogai A, Takayama S (2007) Actin dynamics in papilla cells of Brassica rapa during selfand cross-pollination. Plant Physiol 144(1):72-81

Jiang L, Yang SL, Xie LF, Puah CS, Zhang XQ, Yang WC, Sundaresan V, Ye D (2005) VANGUARD1 encodes a pectin methylesterase that enhances pollen tube growth in the Arabidopsis style and transmitting tract. Plant Cell 17(2):584-596

Kachroo A, Schopfer CR, Nasrallah ME, Nasrallah JB (2001) Allele-specific receptor-ligand interactions in Brassica self-incompatibility. Science 293:1824-1826

Kakita M, Murase K, Iwano M, Matsumoto T, Watanabe M, Shiba H, Isogai A, Takayama S (2007a) Two distinct forms of M-locus protein kinase localize to the plasma membrane and interact directly with S-locus receptor kinase to transduce self-incompatibility signaling in Brassica rapa. Plant Cell 19(12):3961-3973

Kakita M, Shimosato H, Murase K, Isogai A, Takayama S (2007b) Direct interaction between the S-locus receptor kinase and M-locus protein kinase involved in Brassica self-incompatibility signaling. Plant Biotechnol 24:185-190

Kandasamy M, Nasrallah J, Nasrallah M (1994) Pollen-pistil interactions and developmental regulation of pollen tube growth in Arabidopsis. Development (Camb) 120:3405-3418

Kessler SA, Grossniklaus U (2011) She's the boss: signaling in pollen tube reception. Curr Opin Plant Biol 14(5):622-627

Kitashiba H, Liu P, Nishio T, Nasrallah JB, Nasrallah ME (2011) Functional test of Brassica selfincompatibility modifiers in Arabidopsis thaliana. Proc Natl Acad Sci USA 108(44): $18173-18178$

Kusaba M, Dwyer K, Hendershot J, Vrebalov J, Nasrallah JB, Nasrallah ME (2001) Selfincompatibility in the genus Arabidopsis: characterization of the $\mathrm{S}$ locus in the outcrossing A. lyrata and its autogamous relative A. thaliana. Plant Cell 13(3):627-643

Lennon KA, Roy S, Hepler PK, Lord EM (1998) The structure of the transmitting tissue of Arabidopsis thaliana (L.) and the path of pollen tube growth. Sex Plant Reprod 11(1):49-59

Liu J, Zuo X, Yue P, Guo W (2007) Phosphatidylinositol 4,5-bisphosphate mediates the targeting of the exocyst to the plasma membrane for exocytosis in mammalian cells. Mol Biol Cell 18(11):4483-4492

Lolle SJ, Cheung AY (1993) Promiscuous germination and growth of wild-type pollen from Arabidopsis and related species on the shoot of the Arabidopsis mutant, fiddlehead. Dev Biol 155(1):250-258

Lolle SJ, Berlyn GP, Engstrom EM, Krolikowski KA, Reiter WD, Pruitt RE (1997) Developmental regulation of cell interactions in the Arabidopsis fiddlehead-1 mutant: a role for the epidermal cell wall and cuticle. Dev Biol 189(2):311-321 
Lu D, Lin W, Gao X, Wu S, Cheng C, Avila J, Heese A, Devarenne TP, He P, Shan L (2011) Direct ubiquitination of pattern recognition receptor FLS2 attenuates plant innate immunity. Science 332(6036):1439-1442

Luu DT, Heizmann P, Dumas C, Trick M, Cappadocia M (1997) Involvement of SLR1 genes in pollen adhesion to the stigmatic surface in Brassicaceae. Sex Plant Reprod 10(4):227-235

Luu DT, Marty-Mazars D, Trick M, Dumas C, Heizmann P (1999) Pollen-stigma adhesion in Brassica spp. involves SLG and SLR1 glycoproteins. Plant Cell 11(2):251-262

Ma JF, Liu ZH, Chu CP, Hu ZY, Wang XL, Zhang XS (2012) Different regulatory processes control pollen hydration and germination in Arabidopsis. Sex Plant Reprod 25(1):77-82

Mable BK, Robertson AV, Dart S, Di Berardo C, Witham L (2005) Breakdown of selfincompatibility in the perennial Arabidopsis lyrata (Brassicaceae) and its genetic consequences. Evolution 59(7):1437-1448

Mayfield JA, Preuss D (2000) Rapid initiation of Arabidopsis pollination requires the oleosindomain protein GRP17. Nat Cell Biol 2(2):128-130

Mayfield JA, Fiebig A, Johnstone SE, Preuss D (2001) Gene families from the Arabidopsis thaliana pollen coat proteome. Science 292(5526):2482-2485

Murase K, Shiba H, Iwano M, Che FS, Watanabe M, Isogai A, Takayama S (2004) A membraneanchored protein kinase involved in Brassica self-incompatibility signaling. Science 303(5663): 1516-1519

Murphy DJ (2006) The extracellular pollen coat in members of the Brassicaceae: composition, biosynthesis, and functions in pollination. Protoplasma 228(1-3):31-39

Nasrallah ME, Liu P, Nasrallah JB (2002) Generation of self-incompatible Arabidopsis thaliana by transfer of two $S$ locus genes from A. lyrata. Science 297(5579):247-249

Nasrallah ME, Liu P, Sherman-Broyles S, Boggs NA, Nasrallah JB (2004) Natural variation in expression of self-incompatibility in Arabidopsis thaliana: implications for the evolution of selfing. Proc Natl Acad Sci USA 101(45):16070-16074

Nishikawa S, Zinkl GM, Swanson RJ, Maruyama D, Preuss D (2005) Callose (beta-1,3 glucan) is essential for Arabidopsis pollen wall patterning, but not tube growth. BMC Plant Biol 5:22

Paetsch M, Mayland-Quellhorst S, Neuffer B (2006) Evolution of the self-incompatibility system in the Brassicaceae: identification of S-locus receptor kinase (SRK) in self-incompatible Capsella grandiflora. Heredity (Edinb) 97(4):283-290

Postaire O, Tournaire-Roux C, Grondin A, Boursiac Y, Morillon R, Schaffner AR, Maurel C (2010) A PIP1 aquaporin contributes to hydrostatic pressure-induced water transport in both the root and rosette of Arabidopsis. Plant Physiol 152(3):1418-1430

Preuss D, Lemieux B, Yen G, Davis RW (1993) A conditional sterile mutation eliminates surface components from Arabidopsis pollen and disrupts cell signaling during fertilization. Genes Dev 7(6):974-985

Pruitt RE, Vielle-Calzada JP, Ploense SE, Grossniklaus U, Lolle SJ (2000) FIDDLEHEAD, a gene required to suppress epidermal cell interactions in Arabidopsis, encodes a putative lipid biosynthetic enzyme. Proc Natl Acad Sci USA 97(3):1311-1316

Rea AC, Liu P, Nasrallah JB (2010) A transgenic self-incompatible Arabidopsis thaliana model for evolutionary and mechanistic studies of crucifer self-incompatibility. J Exp Bot 61(7): $1897-1906$

Robinson NG, Guo L, Imai J, Toh EA, Matsui Y, Tamanoi F (1999) Rho3 of Saccharomyces cerevisiae, which regulates the actin cytoskeleton and exocytosis, is a GTPase which interacts with Myo2 and Exo70. Mol Cell Biol 19(5):3580-3587

Safavian D, Goring DR (2013) Secretory activity is rapidly induced in stigmatic papillae by compatible pollen, but inhibited for self-incompatible pollen in the Brassicaceae. PLoS One, in press.

Samuel MA, Mudgil Y, Salt JN, Delmas F, Ramachandran S, Chilelli A, Goring DR (2008) Interactions between the S-domain receptor kinases and AtPUB-ARM E3 ubiquitin ligases suggest a conserved signaling pathway in Arabidopsis. Plant Physiol 147(4):2084-2095

Samuel MA, Chong YT, Haasen KE, Aldea-Brydges MG, Stone SL, Goring DR (2009) Cellular pathways regulating responses to compatible and self-incompatible pollen in Brassica and 
Arabidopsis stigmas intersect at Exo70A1, a putative component of the exocyst complex. Plant Cell 21(9):2655-2671

Samuel MA, Tang W, Jamshed M, Northey J, Patel D, Smith D, Siu KW, Muench DG, Wang ZY, Goring DR (2011) Proteomic analysis of Brassica stigmatic proteins following the selfincompatibility reaction reveals a role for microtubule dynamics during pollen responses. Mol Cell Proteomics 10(12), M111.011338

Schierup MH, Mable BK, Awadalla P, Charlesworth D (2001) Identification and characterization of a polymorphic receptor kinase gene linked to the self-incompatibility locus of Arabidopsis lyrata. Genetics 158(1):387-399

Schopfer CR, Nasrallah ME, Nasrallah JB (1999) The male determinant of self-incompatibility in Brassica. Science 286(5445):1697-1700

Shimizu KK, Shimizu-Inatsugi R, Tsuchimatsu T, Purugganan MD (2008) Independent origins of self-compatibility in Arabidopsis thaliana. Mol Ecol 17(2):704-714

Shimosato H, Yokota N, Shiba H, Iwano M, Entani T, Che FS, Watanabe M, Isogai A, Takayama S (2007) Characterization of the SP11/SCR high-affinity binding site involved in self/nonself recognition in Brassica self-incompatibility. Plant Cell 19(1):107-117

Silva NF, Stone SL, Christie LN, Sulaman W, Nazarian KAP, Burnett LA, Arnoldo MA, Rothstein SJ, Goring DR (2001) Expression of the S receptor kinase in self-compatible Brassica napus cv. Westar leads to the allele-specific rejection of self-incompatible Brassica napus pollen. Mol Genet Genomics 265(3):552-559

Stone SL, Arnoldo M, Goring DR (1999) A breakdown of Brassica self-incompatibility in ARC1 antisense transgenic plants. Science 286(5445):1729-1731

Stone S, Anderson E, Mullen R, Goring D (2003) ARC1 is an E3 ubiquitin ligase and promotes the ubiquitination of proteins during the rejection of self-incompatible Brassica pollen. Plant Cell 15(4):885-898

Swanson R, Clark T, Preuss D (2005) Expression profiling of Arabidopsis stigma tissue identifies stigma-specific genes. Sex Plant Reprod 18(4):163-171

Synek L, Schlager N, Elias M, Quentin M, Hauser MT, Zarsky V (2006) AtEXO70A1, a member of a family of putative exocyst subunits specifically expanded in land plants, is important for polar growth and plant development. Plant J 48(1):54-72

Takasaki T, Hatakeyama K, Suzuki G, Watanabe M, Isogai A, Hinata K (2000) The S receptor kinase determines self-incompatibility in Brassica stigma. Nature (Lond) 403(6772):913-916

Takayama S, Shiba H, Iwano M, Asano K, Hara M, Che FS, Watanabe M, Hinata K, Isogai A (2000a) Isolation and characterization of pollen coat proteins of Brassica campestris that interact with S locus-related glycoprotein 1 involved in pollen-stigma adhesion. Proc Natl Acad Sci USA 97(7):3765-3770

Takayama S, Shiba H, Iwano M, Shimosato H, Che FS, Kai N, Watanabe M, Suzuki G, Hinata K, Isogai A (2000b) The pollen determinant of self-incompatibility in Brassica campestris. Proc Natl Acad Sci USA 97(4):1920-1925

Takayama S, Shimosato H, Shiba H, Funato M, Che FS, Watanabe M, Iwano M, Isogai A (2001) Direct ligand-receptor complex interaction controls Brassica self-incompatibility. Nature (Lond) 413(6855):534-538

Takeuchi H, Higashiyama T (2011) Attraction of tip-growing pollen tubes by the female gametophyte. Curr Opin Plant Biol 14(5):614-621

Tang C, Toomajian C, Sherman-Broyles S, Plagnol V, Guo YL, Hu TT, Clark RM, Nasrallah JB, Weigel D, Nordborg M (2007) The evolution of selfing in Arabidopsis thaliana. Science 317(5841):1070-1072

TerBush DR, Maurice T, Roth D, Novick P (1996) The exocyst is a multiprotein complex required for exocytosis in Saccharomyces cerevisiae. EMBO J 15(23):6483-6494

Tsuchimatsu T, Suwabe K, Shimizu-Inatsugi R, Isokawa S, Pavlidis P, Stadler T, Suzuki G, Takayama S, Watanabe M, Shimizu KK (2010) Evolution of self-compatibility in Arabidopsis by a mutation in the male specificity gene. Nature (Lond) 464(7293):1342-1346 
Tung CW, Dwyer KG, Nasrallah ME, Nasrallah JB (2005) Genome-wide identification of genes expressed in Arabidopsis pistils specifically along the path of pollen tube growth. Plant Physiol 138(2):977-989

Updegraff EP, Zhao F, Preuss D (2009) The extracellular lipase EXL4 is required for efficient hydration of Arabidopsis pollen. Sex Plant Reprod 22(3):197-204

Vanoosthuyse V, Miege C, Dumas C, Cock JM (2001) Two large Arabidopsis thaliana gene families are homologous to the Brassica gene superfamily that encodes pollen coat proteins and the male component of the self-incompatibility response. Plant Mol Biol 46(1):17-34

Verdoucq L, Grondin A, Maurel C (2008) Structure-function analysis of plant aquaporin AtPIP2;1 gating by divalent cations and protons. Biochem J 415(3):409-416

Whyte JR, Munro S (2002) Vesicle tethering complexes in membrane traffic. J Cell Sci 115(Pt 13):2627-2637

Wu H, Turner C, Gardner J, Temple B, Brennwald P (2010) The Exo70 subunit of the exocyst is an effector for both $\mathrm{Cdc} 42$ and Rho3 function in polarized exocytosis. Mol Biol Cell 21(3):430-442

Yephremov A, Wisman E, Huijser P, Huijser C, Wellesen K, Saedler H (1999) Characterization of the FIDDLEHEAD gene of Arabidopsis reveals a link between adhesion response and cell differentiation in the epidermis. Plant Cell 11(11):2187-2201

Zhang X, Bi E, Novick P, Du L, Kozminski KG, Lipschutz JH, Guo W (2001) Cdc42 interacts with the exocyst and regulates polarized secretion. J Biol Chem 276(50):46745-46750

Zhang X, Zajac A, Zhang J, Wang P, Li M, Murray J, TerBush D, Guo W (2005) The critical role of Exo84p in the organization and polarized localization of the exocyst complex. J Biol Chem 280(21):20356-20364

Zhang X, Orlando K, He B, Xi F, Zhang J, Zajac A, Guo W (2008) Membrane association and functional regulation of Sec3 by phospholipids and Cdc42. J Cell Biol 180(1):145-158

Zinkl GM, Zwiebel BI, Grier DG, Preuss D (1999) Pollen-stigma adhesion in Arabidopsis: a species-specific interaction mediated by lipophilic molecules in the pollen exine. Development (Camb) 126(23):5431-5440 